\title{
Possible role for nitric oxide releasing nerves in the regulation of ocular blood flow in the rat
}

\author{
Paul A T Kelly, Christine H Buckley, Isobel M Ritchie, Colm O’Brien
}

\begin{abstract}
Aim-To investigate the role of nitrergic nerves in the regulation of ocular blood flow.

Methods-Conscious, lightly restrained rats were treated with either the neuronal nitric oxide synthase inhibitor 7-nitroindazole (7-NI), or the nonselective inhibitor, NG-nitro-L-arginine methyl ester (L-NAME), and ocular blood flow was measured ex vivo from tissue samples, using the fully quantitative [14C]-iodoantipyrine technique.

Results-In the peripheral circulation, L-NAME produced an increase in arterial blood pressure $(+22 \%)$ while $7-\mathrm{NI}$ had no effect. In contrast, both $7-\mathrm{NI}$ and L-NAME produced significant decreases in ocular blood flow $(-31 \%$ and $-59 \%$ respectively). The ocular vascular resistance calculated from ocular blood flow and mean arterial blood pressure increased by $29 \%$ following $7-\mathrm{NI}$, but by $130 \%$ following L-NAME.

Conclusions-Nitric oxide releasing neurons may play an important contributory role in regulating ocular blood flow.

(Br F Ophthalmol 1998;82:1199-1202)
\end{abstract}

There is evidence that ocular blood vessels are innervated by nitric oxide (NO) producing neurons ${ }^{1-3}$ and studies of ocular blood vessels in vitro suggest a functional role for these nerves in determining vascular calibre in the eye. ${ }^{4-6}$ Cerebral vessels are similarly endowed ${ }^{78}$ and it has become apparent that NO released from neurons innervating small cerebral resistance vessels may regulate blood flow by providing a tonic dilator influence. ${ }^{9}$ There is some in vivo evidence that NO releasing nerves can similarly influence blood flow in the avian eye, ${ }^{10}$ but these authors have also reported that anaesthesia can fundamentally alter the cardiovascular response to pharmacological inhibition of neuronal nitric oxide synthase (nNOS), ${ }^{11}$ and others have identified species differences in efficacy and time course of effects. ${ }^{12} 13$ The purpose of the present study was to investigate the effects upon ocular blood flow of a single intraperitoneal injection of the nNOS inhibitor 7-nitroindazole (7-NI), which in vivo is relatively selective for the neuronal isoform of the enzyme, ${ }^{14}$ and to compare these with the effects of the arginine analogue, NG-nitroL-arginine methyl ester (L-NAME), a nonselective NOS inhibitor.

\section{Materials and methods}

ANIMAL PREPARATION

A total of 19 male Sprague-Dawley rats (250$300 \mathrm{~g}$ ) were used in this study. All experiments adhered to the ARVO Statement on the Use of Animals in Ophthalmic and Vision Research, and complied with British Home Office regulations. Protocols did not involve any direct manipulation of the eye. On the day of the experiment the rats were anaesthetised and prepared surgically as described in detail previously. ${ }^{9}$ Following surgery, the rats were allowed to recover from the effects of the anaesthesia for at least 2 hours before any further experimental manipulation, and all subsequent measurements were performed on fully conscious animals. Mean arterial blood pressure (MABP) was monitored continuously, and blood gases were measured immediately before the initiation of the measurement procedures for ocular blood flow.

\section{DRUG TREATMENT}

7-Nitroindazole (Lancaster Synthesis Ltd, Morecambe, Lancs) was suspended in sesame oil $(12.5 \mathrm{mg} / \mathrm{ml})$, taken into solution with mild sonication and kept warm until use. At the end of the recovery period, rats $(\mathrm{n}=5)$ were injected with 7-NI at a dose of $25 \mathrm{mg} / \mathrm{kg}$ via an indwelling intraperitoneal cannula 30 minutes before the measurement of ocular blood flow. In the rat, maximal nNOS inhibition is manifest within 30 minutes following an intraperitoneal injection of $7-\mathrm{NI}$, and the $\mathrm{t}^{1 / 2} / 2$ for the response is of the order of 4 hours. ${ }^{15}$ Control rats were injected with oil alone $(n=4)$. A parallel group of rats were injected intravenously with either L-NAME (30 mg/kg; $\mathrm{n}=5$; Sigma Chemicals) or an equal volume of saline $(0.75$ $\mathrm{ml} ; \mathrm{n}=5) 20$ minutes before the measurement of ocular blood flow.

\section{MEASUREMENT OF OCULAR BLOOD FLOW}

Ocular blood flow was measured using the [14C]-iodoantipyrine method derived by Sakurada et $a l^{16}$ and described in detail previously ${ }^{17}$ with modifications for tissue sampling. ${ }^{18}$ Briefly, [14C]-iodoantipyrine (50 $\mu \mathrm{Ci} / \mathrm{rat}$ in $0.6 \mathrm{ml}$ saline) was injected intravenously over 45 seconds via a femoral cannula, and timed femoral arterial blood samples were collected intermittently. At 45 seconds, the animals were killed by decapitation. Both eyes were rapidly dissected intact from the skull, and placed onto filter paper on an ice cooled dish. The ocular muscles were removed and the eye sliced open at the level of the equator. Tissues from the anterior segments, and the vitreous humour, were removed, and aqueous matter was absorbed onto the filter paper. All 
Table 1 Effects of 7-NI and L-NAME upon physiological measurements

\begin{tabular}{lllll}
\hline & \multicolumn{2}{l}{ Treatment } & & \\
\cline { 2 - 5 } Physiological variables & Oil & $7-N I$ & Saline & L-NAME \\
\hline Ocular blood flow $(\mathrm{ml} / 100 \mathrm{~g} / \mathrm{min})$ & $85(2)$ & $59(7)^{\star}$ & $84(8)$ & $35(4)^{\star}$ \\
Ocular vascular resistance $(\mathrm{mm} \mathrm{Hg} / \mathrm{ml} / 100 \mathrm{~g} / \mathrm{min})$ & $1.54(0.06)$ & $2.46(0.28)^{\star}$ & $1.50(0.05)$ & $4.40(0.31)^{\star}$ \\
$\mathrm{PCO}_{2}(\mathrm{~mm} \mathrm{Hg})$ & $39.6(3.0)$ & $42.1(1.5)$ & $42.0(3.4)$ & $41.2(2.1)$ \\
$\mathrm{PO}_{2}(\mathrm{~mm} \mathrm{Hg})$ & $94.1(3.0)$ & $92.4(4.1)$ & $96.7(5.1)$ & $96.9(5.2)$ \\
$\mathrm{pH}$ & $7.40(0.03)$ & $7.39(0.03)$ & $7.43(0.02)$ & $7.41(0.04)$ \\
$\mathrm{MABP}(\mathrm{mm} \mathrm{Hg})$ & $128(7)$ & $133(7)$ & $125(5)$ & $156(3)^{\star}$ \\
Heart rate (beats/min) & $442(43)$ & $317(18)^{\star}$ & $440(40)$ & $276(41)^{\star}$ \\
No & 4 & 5 & 5 & 5
\end{tabular}

All data are presented as mean (SD) ${ }^{\star}$ Significantly different from appropriate control group, p $<0.05$, Scheffé test.

remaining tissues from the posterior ocular segment, together with blood samples, were processed for liquid scintillation analysis to measure tissue and blood tracer concentrations.

Blood flow was calculated from [14C] concentrations in blood samples taken during the experiments and from the accumulated tracer in ocular tissue samples. The operational equation for the technique ${ }^{16}$ is derived from the Kety-Schmidt ${ }^{19}$ modification of the Fick principle for measurement of blood flow in any organ of the body. In these calculations we used a value of 0.8 for the partition coefficient for ocular tissue. Although this value has been derived empirically for brain $^{16}$ the small volumes of ocular tissue available make it difficult to do likewise for the eye. However, we have found previously ${ }^{20}$ that within the range of flow rates found in the eye, the error introduced to the measurement of flow by using an inappropriate partition coefficient in the range of plus or minus $25 \%$ is only around $3 \%$. An index of ocular vascular resistance was calculated for each individual by dividing mean arterial blood pressure by the value derived experimentally for ocular blood flow, and is reported as $\mathrm{ml} / 100 \mathrm{~g} / \mathrm{min} / \mathrm{mm} \mathrm{Hg}$.

STATISTICAL ANALYSIS

Data are presented as mean (SD). Statistical analyses of the results from physiological measurements and ocular blood flow data were performed by analysis of variance followed by a post hoc Scheffé test to allow multiple pairwise comparisons. Acceptable levels of significance were set at $\mathrm{p}<0.05$.

\section{Results}

Neither 7-NI nor L-NAME had any significant effect upon rectal temperature, arterial $\mathrm{PCO}_{2}$, $\mathrm{PO}_{2}, \mathrm{pH}$, or plasma glucose levels when compared with vehicle injected controls (Table 1). L-NAME did, however, increase MABP significantly $(+22 \%)$, and this was accompanied by a decrease in heart rate $(-38 \%)$. In keeping with previous reports ${ }^{12} 13$-NI at this dose had no significant effect upon MABP at any time throughout the study, but there was a relatively rapid and significant decrease in heart rate $(-28 \%)$ which persisted throughout the experimental period (Table 1).

Despite the dissimilarities in the peripheral response, both drugs produced a significant decrease in ocular blood flow, although this was more marked with L-NAME treatment $(-58 \%$; ranging from 30 to $39 \mathrm{ml} / 100 \mathrm{~g} / \mathrm{min}$ ) than following 7-NI ( $-31 \%$; ranging from 52 to $67 \mathrm{ml} / 100 \mathrm{~g} / \mathrm{min}$ ) (Table 1 ). A very large increase in the calculated ocular vascular resistance following L-NAME (+193\%) reflected the greater effect of L-NAME in reducing ocular blood flow in the face of increased perfusion pressure. This was considerably greater than in the $7-\mathrm{NI}$ treated group $(+60 \%)$ where blood pressure was unaffected by the treatment (Table 1).

\section{Discussion}

The peripheral vascular effects of acute L-NAME treatment observed in this study are similar to those reported previously in this animal model. ${ }^{21} 22$ Moreover, the decrease in ocular blood flow noted here $(-59 \%)$ following L-NAME (intravenously) is both qualitatively and quantitatively similar to our previous data ${ }^{20}$ where L-NAME was injected intraperitoneally, and is of the same order as that found when the constituent parts of the uveal tract were analysed separately in anaesthetised dogs. ${ }^{23}$ In that study, a single intravenous injection of L-NAME resulted in reductions in blood flow of $40 \%, 40 \%$, and $48 \%$ in the choroid, ciliary body, and iris respectively. ${ }^{23}$ More recently, Mann and colleagues, using laser Doppler techniques to measure the short term effects of NOS inhibition on choroidal blood flow in cats, found that the choroid contains vasodilatory cholinergic receptors which, when activated, induce the release of NO from L-arginine. ${ }^{24}$ Taken together, the results of these studies suggest that the tonic synthesis and release of nitric oxide provides dilator tone to the vascular bed of the eye and thus plays a major role in the determination of resting ocular blood flow in different species.

NG substituted arginine analogues are equally effective in inhibiting all isoforms of NOS, and these previous studies do little to identify the relative importance of endothelial and neuronal sources of $\mathrm{NO}$ in the eye. However, a new class of indazole based NOS inhibitors has recently been developed, of which 7-NI is currently the most extensively characterised, which are selective for the neuronal isoform of the enzyme in vivo. ${ }^{12}{ }^{13} \mathrm{In}$ the rat, 7-NI inhibits neuronal NOS in vitro with a potency $\left(\mathrm{IC}_{50}=0.9(\mathrm{SD} 0.1) \mu \mathrm{M}\right)$ equal to that of L-NAME $\left(\mathrm{IC}_{50}=0.9(0.08) \mu \mathrm{M}\right),{ }^{12}$ but there are differences between species in this regard. In the mouse, $7-\mathrm{NI}$ is almost twice as potent as in the rat $\left(\mathrm{IC}_{50}=0.47(0.01) \mu \mathrm{M}\right)$ while L-NAME in comparison is equipotent in both species. ${ }^{12}$ Moreover, in the mouse the 
effect of $7-\mathrm{NI}$ is much shorter lived, and is totally dissipated by 120 minutes following an intraperitoneal injection. ${ }^{13}$

There have to date been no studies on the effects of this drug on human subjects, but 7-NI has been found to attenuate stimulus induced increases in choroid blood flow in the anaesthetised pigeon. ${ }^{10}$ From these studies it was concluded that while constitutive, endothelium derived $\mathrm{NO}$ is involved in the control of resting ocular vascular tone, NO released from neurons plays a role in rapid blood flow responses associated with stimulus induced activation. This could certainly explain the considerable difference in blood flow responses in the eye which we found between L-NAME and 7-NI with a generally quiescent, but not anaesthetised, ocular system. Following the administration of 7-NI in vivo, neuronal NOS activity is inhibited by between $30 \%$ and $40 \%{ }^{14}$ but the lack of any pressor response, even at doses of up to $50 \mathrm{mg} / \mathrm{kg}^{13}$ suggests that $7-\mathrm{NI}$ is indeed selective for the neuronal isoform of the NOS enzyme while having little or no effect upon the endothelial isoform. This is confirmed in the present study where 7-NI produced reductions in ocular blood flow with no effect upon MABP, while in parallel experiments L-NAME induced both peripheral and ocular vasoconstriction. While the decrease in ocular blood flow in response to L-NAME will be the sum of both endothelial and neuronal NOS inhibition in the eye, it is noteworthy that the effect of selective inhibition of neuronal NOS alone is approximately half that of the L-NAME response. Moreover, while ocular vascular resistance was increased by $60 \%$ following 7 -NI, the effects were considerably more marked in L-NAME treated rats (+193\%), reflecting a much greater vasoconstrictor response. Although it might be tempting to speculate on the relative importance of endothelial and neuronal NO production in regulating ocular blood flow, full doseresponse curves to both agents would be necessary before such a conclusion would be acceptable.

Recent reports of an endothelium and nitric oxide synthase independent relaxation of vascular smooth muscle in response to 7-NI in vitro, ${ }^{25}$ question the selectivity of indazole derivatives in inhibiting neuronal NOS. Further in vitro studies have revealed that $7-\mathrm{NI}$ binds to the haem group of the NOS molecule where it competes directly with L-arginine.${ }^{26}$ If 7-NI has a wider capacity to interact with a variety of iron dependent systems (as do other NOS inhibitors), ${ }^{27}$ this could be a possible source of vasoactivity which is independent of NOS inhibition. Whether these effects might also become manifest in vivo remains unclear however. In the majority of studies in which 7-NI has been used no effects upon blood pressure have been observed, suggesting that such effects may only become manifest in very limited physiological conditions, one study clearly identifies an endothelial effect of 7-NI in vivo. ${ }^{11}$ While this observation may thus be at odds with the rest of the literature, including work by the same authors, ${ }^{10}$ anomalous effects of high doses of 7-NI as used in that study have been reported previously by us, ${ }^{9}$ and the issue remains to be resolved.

Although our studies show that neuronally derived NO provides a tonic dilator influence in the ocular circulation, there is evidence for perivascular innervation arising both from within the eye, ${ }^{13}$ and from autonomic ganglia ${ }^{28}$ and it is not possible to determine the relative contributions of these intrinsic and extrinsic neuronal sources to the phenomenon described here.

In conclusion, the results of this study clearly indicate that the vascular sequelae of $7-\mathrm{NI}$ treatment in the ocular circulation of the conscious rat are qualitatively similar to those observed following NG substituted arginine analogues. These results are consistent with the hypothesis that NO, synthesised and released from neuronal (as opposed to endothelial) sources in the eye, has the potential to regulate ocular blood flow. The source of perivascular NO releasing neurons involved in this process deserves closer scrutiny.

This work was funded by the Wellcome Trust.

1 Flügel C, Tamm ER, Mayer B, et al. Species differences in choroidal vasodilative innervation: evidence for specific intrinsic nitrergic and VIP-positive neurons in the human eye. Invest Ophthalmol Vis Sci 1994;35:592-9.

2 Wiencke AK, Nilsson H, Nielsen PJ, et al. Nonadrenergic noncholinergic vasodilation in bovine ciliary artery involves CGRP and neurogenic nitric oxide. Invest Ophthalmol Vis Sci 1994;35:3268-77.

3 Roufail E, Stringer M, Rees S. Nitric oxide synthase immunoreactivity and NADPH diaphorase staining are colocalised in neurones closely associated with the vasculature in rat and human retina. Brain Res 1995;684:36-46.

4 Su EN, Alder VA, Yu DY, et al. Adrenergic and nitrergic neurotransmitters are released by the autonomic system of the pig long posterior ciliary artery. Curr Eye Res 1994;13: $907-17$

5 Toda N, Kitamura Y, Okamura T. Functional role of nervederived nitric oxide in isolated dog ophthalmic arteries. Invest Ophthalmol Vis Sci 1995;36:563-70.

6 Toda N, Toda M, Ayajiki K, et al. Monkey central retinal artery is innervated by nitroxidergic vasodilator nerves. Invest Ophthalmol Vis Sci 1996;37:2177-84.

7 Iadecola C, Beitz AJ, Renno W, et al. Nitric oxide synthasecontaining neural processes on large cerebral arteries and containing microvessels. Brain Res 1993;606:148-55.

8 Regidor J, Edvinsson L, Divac I. NOS neurones lie near branchings of cortical arteriolae. NeuroReport 1993;4:11214.

9 Kelly PAT, Ritchie IM, Arbuthnott GW. Inhibition of neuronal nitric oxide synthase by 7-nitrodiazole: effects upon local cerebral blood flow and glucose use in the rat. $f$ Cereb Blood Flow Metab1995;15:766-73

0 Zagvazdin YS, Fitzgerald ME, Sancesario G, et al. Neural nitric oxide mediates Edinger-Westphal nucleus evoked increase in choroidal blood flow in the pigeon. Invest $\mathrm{Oph}$ thalmol Vis Sci 1996;37:666-72.

11 Zagvazdin YS, Sancesario G, Wang YX, et al. Evidence from its cardiovascular effects that 7-nitroindazole may inhibit endothelial nitric oxide synthase in vivo. Eur $\mathcal{F}$ Pharmacol 1996;303:61-9.

12 Moore PK, Babbedge RC, Wallace P, et al. 7-Nitro indazole, an inhibitor of nitric oxide synthase, exhibits antian inhibitor of nitric oxide synthase, exhibits antipressure. Br f Pharmacol 1993;108:296-7.

13 Moore PK, Wallace P, Gaffen Z, et al. Characterization of the novel nitric oxide synthase inhibitor 7-nitro indazole and related diazoles: antinociceptive and cardiovascular effects. Br F Pharmacol 1993;110:219-24.

14 Babbedge RC, Bland-Ward PA, Hart SL, et al. Inhibition of rat cerebellar nitric oxide synthase by 7-nitro indazole and related indazoles. Br f Pharmacol 1993;110:225-8.

15 MacKenzie GM, Rose S, Jenner P, et al. 7-Nitroindazole is a short-acting inhibitor of brain nitric oxide synthase. $\mathrm{Br} \mathcal{F}$ Pharmacol 1994;112:626P.

16 Sakurada O, Kennedy C, Jehle J, et al. Measurement of cerebral blood flow with iodo-[14C]-antipyrine. Am F Physiol 1978;234:H59-66

17 Kelly PAT, Ritchie IM, McBean DE, et al. Enhanced cerebrovascular responsiveness following depletion of cen-
tral serotonergic terminals. $\mathcal{7}$ Cereb Blood Flow Metab 1995; 15:706-13. 
18 Kelly PAT, Faulkner AJ, Burrow AP. The effects of the GABA agonist muscimol upon blood flow in different vascular territories of the rat cortex. F Cereb Blood Flow Metab 1989;9:766-73.

19 Kety SS, Schmidt CF The nitrous oxide method for the quantitative determination of cerebral blood flow in man theory, procedure and normal values. F Clin Inves 1948;27:476-83.

20 O'Brien C, Kelly PAT, Ritchie IM. Effect of chronic inhibition of nitric oxide synthase upon ocular blood flow and glucose utilization in the rat. Br f Ophthalmol 1997;81:6871 .

21 Macrae IM, Dawson DA, Norrie JD, et al. Inhibition of nitric oxide synthesis: effects of cerebral blood flow and glucose utilisation in the rat. 7 Cereb Blood Flow Metab 1993;13:985-92.

22 Kelly PAT, Thomas CL, Ritchie IM, et al. Cerebrovascular autoregulation in response to hypertension induced by NG-20.
23 Deussen A, Sonntag M, Vogel R. L-arginine-derived nitric oxide: a major determinant of uveal blood flow. Exp Eye Res 993;57:129-34.

24 Mann RM, Riva CE, Stone RA, et al. Nitric oxide and choroidal blood flow regulation. Invest Ophthalmol Vis Sci 1995;36:925-30.

25 Medhurst AD, Greenlees C, Parsons AA, et al. Nitric oxide synthase inhibitors 7- and 6-nitroindazole relax smooth muscle in vitro. Eur f Pharmacol 1994;256:R5-6.

26 Klatt P, Schmid M, Leopold E, et al. The pteridine binding site of brain nitric oxide synthase. Tetrahydrobiopterin binding kinetics, specificity, and allosteric interaction with the substrate domain. F Biol Chem 1994;269:13861-6.

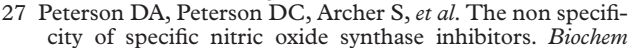
Biophys Res Commun 1992;187:797-801.

28 Yamamoto R, Bredt DS, Snyder SH, et al. The localisation of nitric oxide synthase in the rat eye and related cranial ganglia. Neuroscience 1993;54:189-200. 